\title{
Optical microfibre devices
}

\author{
G. Brambilla \\ Optoelectronics Research Centre, University of Southampton, Southampton SO17 1BJ, U.K. \\ E-mail: gb2@orc.soton.ac.uk
}

\begin{abstract}
In the last decade optical fibre tapers with micrometer diameter (often called microfibers) have been investigated for numerous applications ranging from sensing to wavelength convertors, telecom and optical manipulation. This paper reviews the various applications of microfibres.
\end{abstract}

\section{Optical microfibres}

Although microfibers with diameters comparable to the wavelength have been manufactured for nearly half of a century [1], their application in devices has been limited because of the perceived difficulty to achieve low-loss propagation [2]. Microfibres have been manufactured from a variety of different materials including silica [3-8], silicon [9,10], phosphate [11], tellurite [11], lead-silicate [12], bismuthate [12] and chalcogenide glasses [13] and a variety of polymers [14-19]. Most of the microfibers exhibited an irregular profile along their length which resulted in high propagation losses in devices. In the last decade the use of the flame-brushing technique [3-8] allowed to manufacture microfibers with losses smaller than $0.01 \mathrm{~dB} / \mathrm{mm}$, sufficiently low for the manufacture of devices for sensing, comms, wavelength conversion and optical manipulation.

Optical microfibers (OMs) are optical fibre tapers with diameters comparable to the wavelength of light propagating in them. They generally fabricated by tapering optical fibres and therefore result connected to conventional optical fibres by transition regions (Fig. 1). If the transition region has a suitably small angle, a single mode launched in the optical fibre pigtail core is adiabatically transferred in a single mode guided by the cladding/external medium interface and no power occurs into other modes.

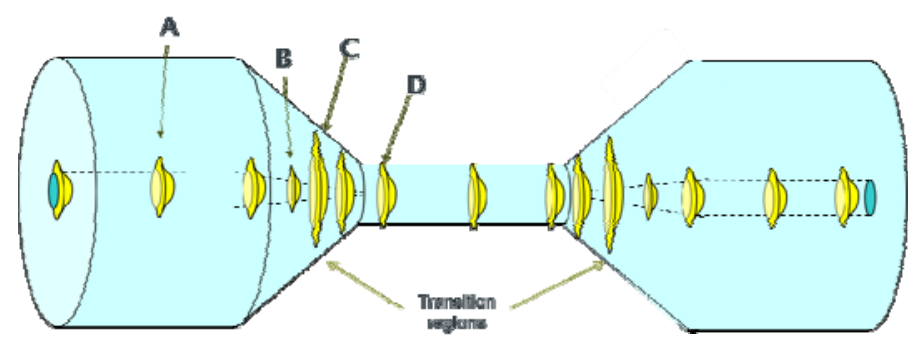

Fig.1 Schematic of operation of an adiabatic optical fibre microwire. A beam launched in the optical fibre pigtail (A) enters the transition region downtaper where it is initially focused (B) until diffraction occurs. The beam then expands and it is guided by the cladding/external medium interface (C). After this point the beam keeps focusing until it reaches the minimum waist diameter (D), where it propagates unaffected. In the uptaper the reverse process occurs and the beam leaved the optical fibre pigtail in the core.

Oms are usually fabricated using the so-called flame brushing technique [4], where a heat source typically a flame - is repeatedly brushed under an optical fibre that is being stretched.

\section{Properties}

Singlemoded OMs have attracted a significant degree of attention over the last decade because they offer a number of enabling properties, which include:

OMs offer a number of enabling properties, which include: 
1) Extremely low losses: the small surface roughness and well defined profile [20,21] provide negligible losses and guidance for a range of diameters down to $\lambda / 10$ [22-27].

2) Configurability: OMs are manufactured from optical fibres, thus they maintain the original optical fibre size at their extremities, allowing for a prompt connection to all fiberized components.

3) Flexibility: OMs can be bent with bending radii of the order of microns, providing devices with minimal footprint.

4) Robustness: because of their negligible surface roughness, OM exhibit an extraordinary mechanical strength [28-21]. Packaging in Teflon or other polymers provide robustness at macroscopic scale [32-35].

5) Large evanescent fields: for diameters smaller than the wavelength, a significant fraction of the mode propagates in the evanescent field, outside the OM [36,37].

6) Strong confinement: for the optimised conditions, an OM can confine a propagating beam to an effective area one order of magnitude smaller than conventional optical fibres, resulting in two orders of magnitude larger nonlinearities and an extremely strong longitudinal component of the electric field [38-41].

7) Biocompatibility: as most of OMs are made from silicate glasses, they have a high compatibility with all biological matter.

This properties have been exploited for the manufacture of numerous devices, which can be grouped into three groups according to the property they exploit:

1) transition regions: the change of mode guidance from core bound to cladding bound allows to convert and filter selected modes. Devices based on this effect include modal filters, modal converters and numerous sensors based on the so-called in-line Mach Zehnder interferometry.

2) confinement; at optimised OM diameters, extremely high intensity in the minimum waist region allow for the prompt observation of strong nonlinear optical effects.

3) evanescent field: the large fraction of the mode propagating outside the OM allows for a strong interaction with the surrounding environment, which has been exploited for sensors, high-Q resonators and optical manipulation.

\section{Transition regions}

The transition regions connect the OM to the regular fibres (Fig.1) and allow for a mode transition from core guidance to cladding guidance [42-44]. If the conversion is on one-to-one basis and there is no power transfer between different modes, the taper is called adiabatic. If $\beta_{1}$ and $\beta_{2}$ are the propagation constants of two modes propagating in a fibre with radius $r$, and $z_{b}$ their beat length, the taper is considered adiabatic if at any radius its local angle $\Omega$ is smaller than a critical angle $\bar{\Omega}$ given by:

$\Omega<\bar{\Omega}=\frac{r}{z_{b}}=\frac{r\left(\beta_{1}-\beta_{2}\right)}{2 \pi}$

For $\Omega \geq \bar{\Omega}$ the taper is not considered adiabatic and core modes can couple to higher-order cladding modes with the same azimuthal symmetry which can be leaked out of the fibre if that specific mode is not supported in the uniform waist region (Fig. 2).

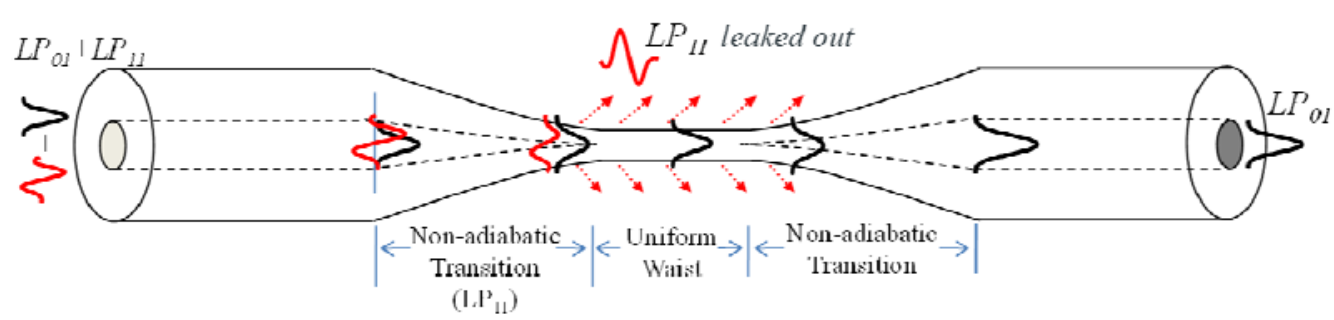

Fig.2 Schematic of operation of an optical microfiber with non-adiabatic transition regions. Two (or more) modes are injected in the optical fibre pigtail. In the transition region the higher order mode $\left(\mathrm{LP}_{11}\right)$ exchange power with even higher order modes that can be leaked out if not supported by the OM in the uniform waist region. 
This effect has been exploited to eliminate high order modes from few mode fibres and couplers [4547], selective excitation of fundamental mode in few mode fibres [48], interferometric sensors in taper tips [49], and comb-like filters for tunable lasers [50]. In the minimum waist region the mode propagating in the $\mathrm{OM}$ is effectively guided by the cladding/air interface and it is not affected by the relative core size in its pigtails. The possibility to selectively excite the fundamental mode can find application in high power fibre lasers, where single mode operation in large cores are utilised to maximise the laser brightness [51].

The non-adiabatic taper profile has found broad application in sensing, as the excitation of multiple modes and their beating resulted in the so-called in-line Mach-Zehnder interferometers.

\section{Confinement}

OMs usually provide efficient modal confinement to sizes smaller than the wavelength, resulting in enhanced nonlinearity $\gamma$ and in phenomena like supercontinuum generation [52-57], second- and third-harmonic generation [58-71], slow and fast light [72] and bistability [72-74] being readily observed.

Supercontinuum was generated in silica [6], bismuth-silicate [12] and chalcogenide [75] glasses. In silica OM, supercontinuum has been generated over two octaves [76-79]; yet, the small size affects the overall dispersion profile resulting in a poorer spectral flatness [80]. For increasing powers, a decreasing degree of coherence has been observed and was attributed to phase noise [81]. The mechanism originating supercontinuum has been investigated both for fs- and for ps-pulses [82]: while in the former self phase modulation and solitons [83] are the most important phenomena, in the latter four wave mixing dominates.

High-order harmonics has also been generated in OMs and benefited from the possibility to achieve both phase matching and high overlap between modes at different wavelengths [84-85]. The significantly lower refractive index of the surrounding medium compensates for the increasing OM refractive index at shorter wavelengths. Fig. 3 shows the effective index dispersion for different modes at the fundamental and third harmonic frequencies, showing that intermodal phase matching can occur with different modes at different diameters. This is a particularly interesting effect because it allows for the efficient generation of different wavelengths without an external nonlinear crystal.

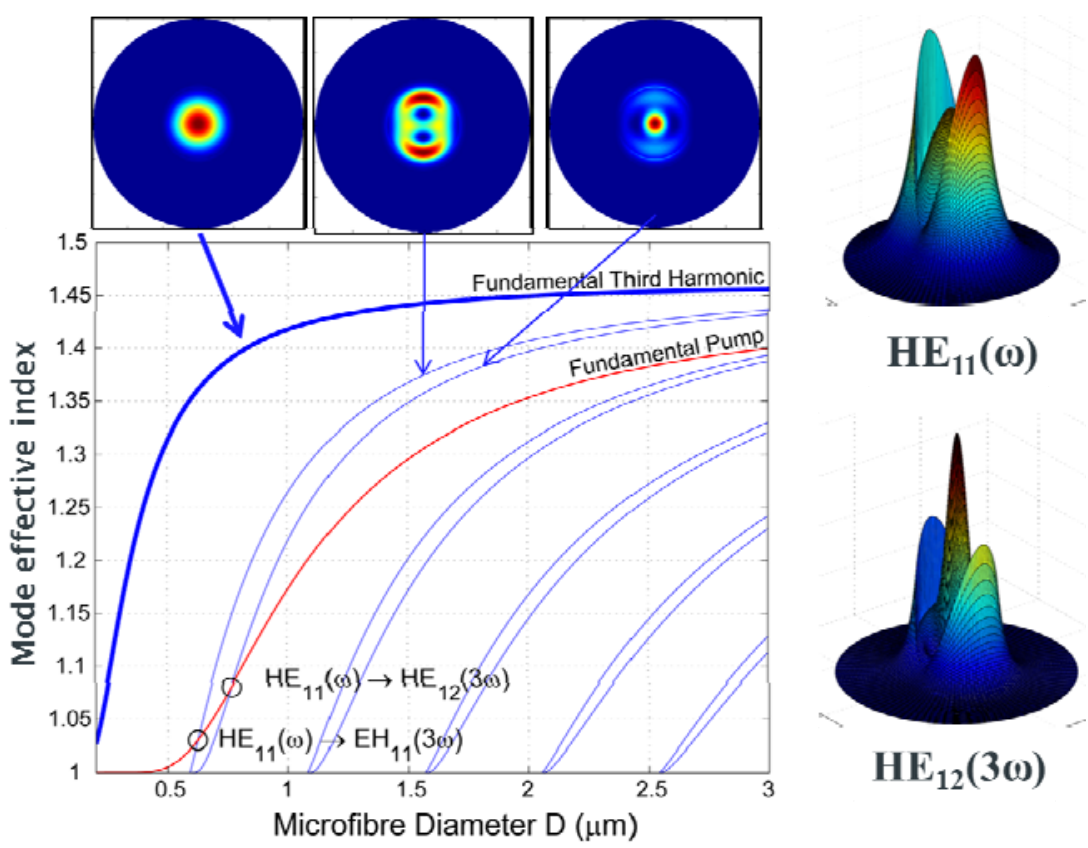

Fig.3 Effective index dispersion at $\lambda=1.55 \mu \mathrm{m}$ for the fundamental mode at the pump wavelength $\omega$ and high order modes at the third harmonic wavelength $3 \omega$. Different phase matching diameters exist for different modes at different effective indices. The mode field profile of $\mathrm{HE}_{11}$ and $\mathrm{HE}_{12}$ modes at the phase matching diameter are shown on the right. 
For optimised diameters, in phase matching conditions the overlap can reach 70\% [38]. Experiments carried out on a $100 \mu \mathrm{m}$-long OM with $\mathrm{r}=245 \pm 10 \mathrm{~nm}$ have demonstrated a conversion efficiency of $2 \cdot 10^{-6}$ [58]. The low detected efficiency has been explained by the irregular diameter profile associated to thermal surface waves trapped during solidification in the OM [65]. Efficiencies larger than $60 \%$ have been predicted for optimised OM with an idea diameter [38]. Second harmonic was also generated, albeit with an efficiency one order of magnitude lower than that observed in the thirdharmonics experiments [58]. Because of the predicted high conversion efficiency, OMs have been proposed for third-order parametric amplifiers [86].

When cleaved, the OM has a rapidly divergent beam that has been exploited to optically trap particles $[87,88]$. Trapping of a single particle at the OM tip was carried out with a power slightly higher than10mW [89], lower than those used in free space (1W) [90] or with lensed fibres (22mW) [91-93].

Because of their minimal footprint, OM have found numerous applications in in-vivo, in-situ intracellular sensing.

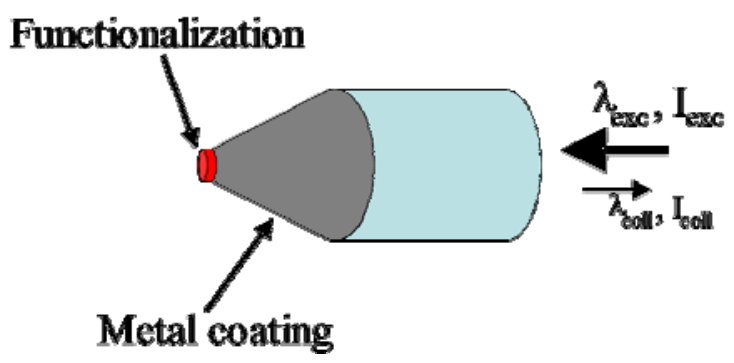

Fig.4 Schematic of an OM tip sensor used for in-vivo, in-situ monitoring of molecules of particular interest in biological applications. The tip is coated with a thin layer of metal and its distant end is functionalised with a highly selective receptor which emits light at the wavelength $\lambda_{\text {coll }}$ when excited at $\lambda_{\text {exc }}$.

Fig. 4 shows a common configuration for OM tips used in biological sensing: the OM tip is metal coated [94] and a small aperture is left at end face for functionalization and covalent immobilization of biorecognitors. Fluoresceinamine photo-copolymerised with acrylamide-methylenebis(acrylamide) was used for $\mathrm{pH}$ sensing [94]; antibodies allowed to detect benzopyrene tetrol, and benzo[ $\alpha$ ]pyrene [95-99], cytochrome c [100] and caspase-9 [101]. Plasticized polymeric membranes coatings were used to detect ions [102], including potassium [101], calcium [103] and nitric acid [104].

\section{Evanescent field}

When the OM diameter becomes smaller than the wavelength, an increasingly large fraction of the mode in propagating in the evanescent field and can interact with the surrounding environment. This has been exploited in a number of sensors, for optical manipulation, high-Q resonators and even gratings.

OM based sensors rely on the change in the propagation mode resulting from a change in the surrounding environment. Hydrogen [105], humidity [106] $\mathrm{NO}_{2}$ and $\mathrm{NH}_{3}$ [16], refractive index [107] and even sub-monolayers of 3,4,9,10-perylene-tetracarboxylic dianhydride (PTCDA) [108] have been monitored with OM sensors.

Optical manipulation relies on the momentum of the photons traveling in the evanescent field to propel particles in close proximity of the OM surface. Optical propulsion has been demonstrated for $3 \mu \mathrm{m}$ [109] and 10 $\mu \mathrm{m}$ [110] polystyrene microspheres using the fundamental and high order modes[111], cells [112], nanoparticles [113], molecules [114] and even atoms [115-118]. Because of the geometry, atom fluorescence can be efficiently collected into the OM guided mode [119], resulting in wide applications in quantum optics [120-127], electromagnetically induced transparency [128] and slow light [129].

High-Q resonator exploit the evanescent field to couple the mode back into a different section of the OM where it previously travel: the modes propagating in the two different OM sections can couple, 
creating an extremely compact resonator. Different geometries have been proposed (fig. 5): knot [130140], loop [141-147] and microcoil [24-27,148-152].

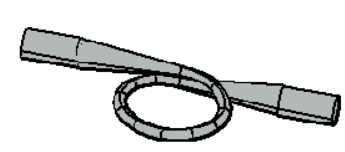

a)

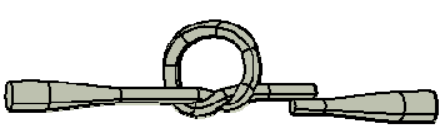

b)

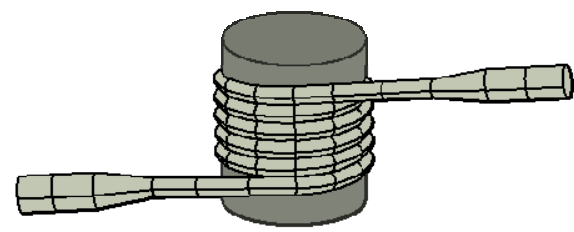

c)

Fig. 5 Schematic diagram of OM resonators: (a) loop; (b) knot and (c) microcoil.

Embedding has been proposed [131] to improve the resonator stability and durability. Application to lasing has been demonstrated using an Er:Yb-doped phosphate glass OM [132], by immersing a KR in a rhodamine 6G dye solution [135] and using zinc oxide nanowires [136] on the OM surface. Resonating sensors have been proposed for biological applications [144], refractometrics [145-146, 151-152], and electric current [147].

As a large fraction of power propagates in the evanescent field, by positioning an OM in proximity of a periodical structure, it is possible to form external gratings [153] which can be used for sensing [154-156]. Bragg gratings and long period gratings have been inscribed in OMs also using ion-beam milling [157] fs and $\mathrm{CO}_{2}$ lasers [158] and lead to numerous applications of OM gratings [159]. The OM large evanescent field has also been used in conjunction with graphene to modulate light and sensing applications [160-162].

\section{Conclusions and outlook}

This review analyses optical microfibers (OMs) and their applications in devices and sensors. OMs devices have been grouped according to the property they exploit: transition regions, confinement or evanescent field. Although a relatively new platform, devices based on OM promise a tremendous impact, especially in nonlinear optics, quantum optics and sensing.

Because of their nature, OM exhibit few issues, most notably the optical degradation, the mechanical robustness and above all the relatively high cost of photonics technologies with respect to their electronic counterparts. While degradation and robustness are easily addressed by suitable packaging (or working in vacuum, for quantum optics), the cost element will remain a main issue and will most probably limit the OM applications into fields were electromagnetic interference and accessibility remain an issue or in research labs, where they provide better performance than conventional bulk optical components.

In particular, it is easy to predict that in the near future OM will find a broad range of applications in the quantum optics field, where the greater collection efficiency of photons allows for easier experimental set-ups, in nonlinear optics, where the tunable dispersion characteristics and high nonlinearity allow for easy observation of nonlinear effects, and in nanosensing, where the small footprint allows for invasive measurements in biological entities.

Acknowledgment: The author gratefully acknowledges the Royal Society (London, U.K) for his research fellowship (grant UF110123) and the UK engineering and physical sciences research council (EPSRC, grant EP/L01243X/1) for financial support. He also thanks for their valuable help: T. Lee, D. Ming, R. Ismaeel, M.I.M. Abdul Khudus, G. Chen, P. Wang, F. Xu, P. Horak, Y. Jung, X. Feng, S.G. Murugan, T. Newson, J.S. Wilkinson, D.J. Richardson and D.N. Payne.

\section{Reference}

[1] Marcuse D, and Derosier R M 1969 Bell Syst. Tech. J. 48 3217-32.

[2] Tong LM, Gattass RR, Ashcom JB, He SL, Lou JY, Shen MY, Maxwell I, and Mazur E 2003

Nature 426 816-9.

[3] Bures J, and Ghosh R 1999 J. Opt. Soc. Am. A 16 1992-6.

[4] Bilodeau F, Hill KO, Johnson DC, and Faucher S 1987 Opt. Lett. 12 6-636.

[5] Brambilla G, Finazzi V, and Richardson DJ 2004 Opt. Express 12, 2258-63. 
[6] Leon-Saval SG, Birks TA, Wadsworth WJ, Russell PStJ, and Mason MW 2004 Opt. Express 12 2864-69.

[7] Clohessy AM, Healy N, Murphy DF, and Hussey CD 2005 Electron. Lett. 41 27-29.

[8] Brambilla G, Xu F, and Feng X 2006 Electron. Lett. 42 517-8.

[9] Yan HF, Xing YJ, Hang QL, Yu DP, Wang YP, Xu J, Xi ZH, and Feng SQ 2000 Chem. Phys. Lett. 323 224-8.

[10] Liu ZQ, Zhou WY, Sun LF, Tang DS, Zou XP, Li YB, Wang CY, Wang G, and Xie SS 2001 Chem. Phys. Lett. 341, 523-8.

[11] Tong L, Hu L, Zhang J, Qiu J, Yang Q, Lou J, Shen Y, He J, and Ye Z 2006 Opt. Express 14 82-7.

[12] Brambilla G, Koizumi F, Feng X, and Richardson DJ 2005 Electron. Lett. 41 400-2.

[13] Mägi EC, Fu LB, Nguyen HC, Lamont MRE, Yeom DI, and Eggleton BJ 2007 Opt. Express 15 10324-9.

[14] Harfenist SA, Cambron SD, Nelson EW, Berry SM, Isham AW, Crain MM, Walsh KM, Keynton RS, and Cohn RW 2004 Nanoletters 4 1931-7.

[15] Nain A S, Wong J C, Amon C and Sitti M 2006 Appl. Phys. Lett. 89 183105-7.

[16] Gu FX, Zhang L, Yin XF, and Tong LM 2008 Nano Lett. 8 2757-61.

[17] Xing X, Wang Y, and Li B 2008 Opt. Express 16 10815-22.

[18] Guo M, Shi J, and Li B 2008 Opt. Lett. 33 2104-6.

[19] Tong LM, Lou JY, Ye ZZ, Geoff TS, and Mazur E 2005Nanotechnology 16 1445-8.

[20] Birks TA, and Li YW 1992 J. Lightwave Technol. 10 432-8.

[21] Love JD, Henry WM, Stewart WJ, Black RJ, Lacroix S, and Gonthier F 1991 IEE Proceedings-J 138 343-54.

[22] Sumetsky M 2004 Opt. Express 12 2303-16.

[24] Kovalenko AV, Kurashov VN, and Kisil AV 2008 Opt. Express 16 5797-806

[24] Sumetsky M 2006 Opt. Lett. 31 870-2.

[25] Sumetsky M 2006 Opt. Lett. 31 3420-2.

[26] Sumetsky M, Dulashko Y, Domachuk P, and Eggleton BJ 2007 Opt. Lett. 32 754-6.

[27] Sumetsky M 2007 Opt. Express 15 1480-90.

[28] Brambilla G, and Payne DN 2009 Nano Lett. 9(2) 831-5.

[29] Silva ECCM, Tong LM, Yip S, and Van Vliet KJ 2006 Small 2 239-43.

[30] Wang ZL, Gao RP, Poncharal P, De Heer WA, Dai ZR, and Pan ZW 2001 Mater. Sci. Eng. C 16 3-10.

[31] Dikin DA, Chen X, Ding W, Wagner G, and Ruoff RS J. Appl. Phys. 93 226-30.

[32] Xu F, and Brambilla G 2008 Jap. J. Appl. Phys. 47 6675-7.

[33] Xu F, and Brambilla G 2007 Opt. Lett. 32 2164-6.

[34] Vienne G, Li YH, and Tong LM, 2007 Photon. Technol. Lett. 19 1386-8.

[35] Vienne G, Li YH, Tong LM, 2007 IEICE Trans. Electron. E90-C 415-21.

[36] Okamoto K, Fundamentals of Optical Waveguides 2000 Academic Press.

[37] Tong LM, Lou JY, and Mazur E 2004 Opt. Express 12, 1025-35.

[38] Grubsky V, and Savchenko A 2005 Opt. Express 13, 6798-806.

[39] Brambilla G, Xu F, Horak P, Jung Y, Koizumi F, Sessions NP, Koukharenko E, Feng X, Murugan GS, Wilkinson JS, and Richardson DJ 2009 Adv. Opt. Photon. 1 107-61.

[40] Afshar VS, Monro TM, 2009 Opt. Express 17 2298-2318.

[41] Afshar VS, Zhang WQ, Ebendorff-Heidepriem H, Monro TM, 2009 Opt. Lett. 34 (22), $3577-$

3579 .

[42] Love JD, Henry WM, Stewart WJ, Black RJ, Lacroix S, and Gonthier F 1991 IEE

Proceedings-J 138 343-54.

[43] Black RJ, Lacroix S, Gonthier F, and Love JD 1991 IEE Proceedings-J 138 355-64.

[44] Jung Y, Brambilla G, and Richardson DJ 2008 Opt. Express 16 14661-7.

[45] Jung Y, Brambilla G, and Richardson DJ 2008 Opt. Express 16 14661-7.

[46] Jung Y, Brambilla G, and Richardson DJ 2009 Opt. Express 17 5273-8.

[47] Jung Y, Brambilla G, and Richardson DJ 2009 Opt. Express 17 16619-24.

[48] Jung Y, Jeong Y, Brambilla G, and Richardson DJ 2009 Opt. Lett. 34 2369-71. 
[49] Zhu Y, Chen X, and Wang A 2009 Opt. Lett. 34 2808-10.

[50] Li Y, and Bao X 2008 Appl. Phys. Lett. 93261107.

[51] Dawson JW, Messerly MJ, Beach RJ, Shverdin MY, Stappaerts EA, Sridharan AK, Pax PH, Heebner JE, Siders CW, and Barty CPJ 2008 Opt. Express 16 13240-66.

[52] Foster M, Gaeta A, Cao Q, and Trebino R 2005 Opt. Express 13 6848-55.

[53] Foster MA, Dudley JM, Kibler B, Cao Q, Lee D, Trebino R, and Gaeta AL 2005 Appl. Phys. B:Lasers and Optics. 81 363-7.

[54] Gattass RR, Svacha GT, Tong L, and Mazur E 2006 Opt. Express 14 9404-14.

[55] Price JHV, Monro TM, Ebendorff-Heidepriem H, Poletti F, Horak P, Finazzi V, Leong JYY, Petropoulos P, Flanagan JC, Brambilla G, Feng X, and Richardson DJ 2007 IEEE Journal of Selected Topics in Quantum Electronics 13 738-49.

[56] Birks TA, Wadsworth WJ, and Russell PStJ 2000 Opt. Lett. 25 1415-17.

[57] Cordeiro CBC, Wadsworth WJ, Birks TA, and Russell PStJ 2005Opt. Lett. 30 1980-2.

[58] Grubsky V, and Feinberg J 2007 Opt. Commun. 274 447-50.

[59] Lee T., Jung Y., Codemard C.A., Ding M., Broderick N.G.R., Brambilla G. 2012 Opt.

Express 20(7) 8503-8511

[60] Ismaeel R.M.N., Lee T., Ding M., Broderick N.G.R., Brambilla G.2012 Opt. Lett. 37 5121-

5123

[61] Lee T., Broderick N.G.R., Brambilla G. 2013 J. Opt. Soc. Am. B 30(3) 505-511

[62] Huang T., Shao X., Wu Z., Lee T., Sun Y., Lam H.Q., Zhang J., Brambilla G., Ping P. 2013 Opt. Express 2013 21(23) 28403-28413

[63] Huang T., Shao X., Wu Z., Lee T., Wu T., Sun Y., Zhang J., Lam H.Q., Brambilla G., Shum P.P. 2014 IEEE Phot. J. 6(3) 4800607

[64] Sun Y., Shao X., Huang T., Wu Z., Lee T., Shum P.P., Brambilla G., 2014 J. Opt. Soc. Am. B 31(9) 2142-2149

[65] Abdul Khudus M.I.M., Lee T., Huang T., Shao X., Perry P.P., Brambilla G. 2015 Fiber Integ. Opt. 2015 34(1-2) 53-65

[66] Gouveia M.A., Lee T., Ismaeel R., Ding M., Broderick N.G.R., Cordeiro C.M.B., Brambilla G. 2013 Appl. Phys. Lett. 102201120

[67] Coillet A., Grelu P. 2012 Opt. Comm. 285 3493-3497

[68] Lægsgaard J. 2010 J. Opt. Soc. Am. B 27 1317-1324

[69] Grubsky V. Savchenko A. 2015 Opt. Express 136798

[70] Wiedemann U., Karapetyan K., Dan C., Pritzkau D., Alt W., Irsen S., Meschede D. 2010 Opt. Express 187693

[71] Richard S. 2010 J. Opt. Soc. Am. B 27 1504-1512

[72] Broderick NG 2008 Opt. Express 16, 16247-54.

[73] Vienne G, Li Y, Tong L, and Grelu P 2008 Opt. Lett. 33, 1500-2

[74] Vienne G, Grelu P, Pan X, Li Y, and Tong L 2008 J. Opt. A: Pure Appl. Opt. 10025303.

[75] Yeom D, Mägi EC, Lamont MRE, Roelens MAF, Fu L, and Eggleton BJ 2008 Opt. Lett. 33, 660-2.

[76] Gopinath JT, Shen HM, Sotobayashi H, Ippenet EP, Hasegawa T, Nagashima T, and Sugimoto N 2004 Opt. Express 12 5697-703.

[77] Husakou AV, and Herrmann J 2003 Appl. Phys. B 77 227-234.

[78] Brambilla G, Mills J, Finazzi V, and Koizumi F 2006 Electron. Lett. 42 574-5.

[79] Wadsworth WJ, Ortigosa-Blanch A, Knight JC, Birks TA, Mann TPM, and Russell PStJ 2002 J. Opt. Soc. Am. B 19 2148-55.

[80] Teipel J, Franke K, Türke D, Warken F, Meiser D, Leuschner M, and Giessen H 2003 Applied Physics B Lasers and Optics, 77 245-51.

[81] Türke D, Pricking S, Husakou A, Teipel J, Herrmann J, and Giessen H 2007 Opt. Express 15 2732-41.

[82] Dudley JM, Genty G, and Coen S 2006 Rev. Mod. Phys. 78, 1135-84.

[83] Foster MA, Gaeta AL, Cao Q, and Trebino R 2005 Opt. Express 13 6848-55.

[84] Zheltikov AM Optika i spektroskopiya 95 440-6.

[85] Akimov DA, Ivanov AA, Naumov AN, Kolevatova OA, Alfimov MV, Birks TA, Wadsworth WJ, Russell PStJ, Podshivalov AA, and Zheltikov AM 2003 Appl. Phys. B 76 515-9. 
[86] Chapron D, and Voss PL 2008 Proc. Int. Conf. IEEE/LEOS Winter Topical Meeting (Sorrento, Italy, 14-16 January 2008) 63-4

[87] Ashkin A, Dziedzic JM, Bjorkholm JE, and Chu S1986 Opt. Lett. 11 288-90.

[88] Grier DG 2003 Nature 424 810-6.

[89] Brambilla G, and Xu F 2006 Electron. Lett. 43 204-5

[90] Ashkin A 1997 Biophys. 94 4853-60.

[91] Lyons ER, and Sonek GJ 1995 Appl. Phys. Lett. 66 1584-6.

[92] Taguchi K, Atsuta K, Nakata T, and Ikeda M, Opt. Quantum Electron. 33 99-106.

[93] Hu ZH, Wang J, and Liang JW, 2004 Opt. Express 12 4123-8.

[94] Tan WH, Shi ZY, and Kopelman R 1992 Anal Chem 64 2985-90

[95] Vo-Dinh T, Alarie JP, Cullum BM, and Griffin GD 2000 Nat. Biotechnol. 18 764-7.

[96] Cullum B, Griffin GD, Miller GH, and Vo-Dinh T 2000 Anal. Biochem. 277 25-32.

[97] Vo-Dinh T, and Cullum B 2000 Fresenius J. Anal. Chem. 366 540-51.

[98] Vo-Dinh T, Griffin GD, Alarie JP, Cullum BM, Sumpter B, and Noid DJ 2000 J. Nanopart. Res. 2 17-27.

[99] Kasili PM, Cullum BM, Griffin GD, and Vo-Dinh T 2002 J. Nanosci. Nanotech. 2 653-8.

[100] Kasili PM, Song JM, Vo-Dinh T (2004) J. Am. Chem. Soc. 9 2799-806.

[101] Song JM, Kasili PM, Griffin GD, and Vo-Dinh T 2004 Anal. Chem. 76 2591-4.

[102] Koronczi I, Reichert J, Heinzmann G, and Ache HJ 1998 Sens. Actuators B 51 188-95

[103] Bui JD, Zelles T, Lou, HJ, Gallion VL, Phillips MI, and Tan W 1999 J-Neurosci-Methods 89

9-15.

[104] Barker SLR, and Kopelman R 1998 Anal. Chem. 70 4902-6.

[105] Villatoro J, and Monzón-Hernández D Opt. Express 13 5087-92.

[106] Zhang L, Gu F, Lou J, Yin X, and Tong L 2008 Opt. Express 16 13349-53.

[107] Polynkin P, Polynkin A, Peyghambarian N, and Mansuripur M 2005 Opt. Lett. 30 1273-5.

[108] Warken F, Vetsch E, Meschede D, Sokolowski M, and Rauschenbeutel A 2007 Opt. Express 15 11952-8.

[1091] Brambilla G, Murugan GS, Wilkinson JS, and Richardson DJ 2007 Opt. Lett. 32 3041-3.

[110] Murugan GS, Brambilla G, Wilkinson JS, and Richardson DJ 2008 Jap. J. Appl. Phys. 47 6716-8.

[111] Maimaiti A., Giang Truong V., Sergides M., Gusachenko I., Nic Chormaic S. 2015 Sci. Rep. 5, 9077

[112] Xin, H., Xu, R., Li, B. 2013 Laser Photon. Rev. 7, 801-809.

[113] Wang SS, Pan XY, Tong LM 2007 Opt. Commun. 276 293-7.

[114] Morrissey, M.J.; Deasy, K.; Frawley, M.; Kumar, R.; Prel, E.; Russell, L.; Truong, V.G.; Nic Chormaic, S. 2013 Sensors 13, 10449-10481.

[115] Balykin VI, Hakuta K, Le Kien F, Liang JQ, and Morinaga M 2004 Phys. Rev. A 70011401.

[116] Kien FL, Balykin VI and Hakuta K 2004 Phys. Rev. A 70063403.

[117] Sagué G, Baade A, and Rauschenbeutel A 2008 New J. Phys. 10113008.

[118] Fu J, Yin X, Li NY, and Tong LM 2008 Chin. Opt. Lett. 6 112-5.

[119] Le Kien F, Dutta Gupta S, Balykin VI, and Hakuta K 2005 Phys. Rev. A 72032509.

[120] Nayak KP, Melentiev PN, Morinaga M, Le Kien F, Balykin VI, and Hakuta K 2007 Opt. Express 15 5431-8.

[121] Sague G, Vetsch E, Alt W, Meschede D, and Rauschenbeutel A 2007 Phys. Rev. Lett. 99 163602.

[122] Morrissey MJ, Deasy K, Wu Y, Chakrabarti S, and Nic Chormaic S 2009 Rev. Sci. Instrum. 80053102.

[123] Nayak KP, and Hakuta K 2008 New J. Phys. 10053003.

[124] Minogin VG, and Chormaic SN 2009 Laser Phys. ISSN 1054-660X (Print) 1555-6611 (Online)

[125] Russell L, Gleeson DA, Minogin VG, and Nic Chormaic S 2009 J. Phys. B: At. Mol. Opt. Phys. 42185006.

[126] Le Kien F, and Hakuta K 2009 Phys. Rev. A 79043813.

[127] Le Kien F, and Hakuta K 2009 Phys. Rev. A 77033826.

[128] Le Kien F, Dutta Gupta S, Nayak KP, and Hakuta K 2005 Phys. Rev. A 72063815. 
[129] Le Kien F, and Hakuta K 2009 Phys. Rev. A 79013818.

[130] Jiang XS, Tong LM, Vienne G, Guo X, Tsao A, Yang Q, and Yang DR 2006 Appl. Phys. Lett. 88223501.

[131] Vienne G, Li YH, Tong LM 2007 IEEE Photon. Technol. Lett. 19 1386-8.

[132] Jiang XS, Yang Q, Vienne G, Li YH, Tong LM, Zhang JJ, and Hu LL2006 Appl. Phys. Lett. 89143513.

[133] Li YH, Vienne G, Jiang XS, Pan XY, Liu X, Gu PF, and Tong LM 2006 Opt. Express 14 7073-6.

[134] AlOrainy A, Li YH, and Tong LM 2008 Opt. Commun. 281 3000-3.

[135] Jiang XS, Song QH, Xu L, Fu J, and Tong LM 2007 Appl. Phys. Lett. 90233501.

[136] Yang Q, Jiang XS, Guo X, Chen YC, and Tong LM 2009 Appl. Phys. Lett. 94101108.

[137] Jiang XS, Chen Y, Vienne G, and Tong LM 2007 Opt. Lett. 32 1710-2.

[138] Chen G, Zhang Y, Huang D, Zhang X, Cao H and Chen W 2009 Opt. Commun. 282 2552-5.

[139] Vienne G, Grelu P, Li YH, and Tong LM 2008 Opt. Lett. 33 1500-2.

[140] Vienne G, Coillet A, Grelu P, El Amraoui M, Jules JC, Smektala F, and Tong LM 2009 Opt. Express 17 6224-9.

[141] Sumetsky M, Dulashko Y, Fini JM, and Hale A 2005 Appl. Phys. Lett. 86161108.

[142] Caspar C, and Bachus EJ 1989 Electron. Lett. 25 1506-8.

[143] Pal P, and Knox WH 2009 Photon. Technol. Lett. 21 766-8.

[144] Shi L, Xu L, Tan W, and Chen X 2007 Sensors 7 689-96.

[145] Xu F, Pruneri V, Finazzi V, and Brambilla G 2008 Opt. Express 16 1062-7.

[146] Guo X, and Tong LM, 2008 Opt. Express 16 14429-34.

[147] Guo X, Li Y, Jiang X, and Tong LM 2007 Appl. Phys. Lett. 91073512.

[148] Xu F, and Brambilla G 2007 Photon. Technol. Lett. 19 1481-3.

[149] Xu F, Horak P, and Brambilla G 2007 Appl. Opt. 46 570-3.

[150] Xu F, Horak P, and Brambilla G 2007 J. Lightwave Technol. 25 1561-7.

[151] Xu F, Horak P, and Brambilla G 2007 Opt. Express 15 7888-93.

[152] Xu F, and Brambilla G 2008 Appl. Phys. Lett. 92101126.

[153] Xu F, Brambilla G, Feng J, and Lu Y 2010 Photon. Technol. Lett. 22

[154] Xu F, Brambilla G, and Lu YQ 2009 Opt. Express 17 20866-71.

[155] Luo W, Kou J, Chen Y, Xu F, Lu Y 2012, Appl. Phys. Lett. 101 (13), 133502

[156] Luo W., Kou J., Chen Y., Xu F., Lu Y. 2013 Appl. Phys. Lett. 101 (13), 133502

[157] Luo W, Xu F, Lu Y 2015 Phys. Rev. A 91, 053831

[158] Xuan H, Jin W, and Zhang M 2009 Opt. Express 17 21882-90.

[159] Kou JL, Ding M, Feng J, Lu YQ, Xu F, Brambilla G, Sensors 12 (7), 8861-8876

[160] Kou JL, Chen JH, Chen Y, Xu F, Lu Y 2014 Optica 1 307-310

[161] Yu S, Meng C, Chen B, Wang H, Wu X, Liu W, Zhang S, Liu Y, Su Y, Tong L 2015 Opt. Express 23(8) 10764-10770

[162] Wu Y, Yao B, Cheng Y, Rao YJ, Gong Y, Zhang W, Wang Z, Chen Y 2014 IEEE Sel. Top. Quantum Electron. 204400206 